\title{
Research of Cultivating University Students' Innovation Ability based on Technological Competition
}

\author{
Deng Yaohua ${ }^{1, a}$, Chen Sicheng ${ }^{1, a}$, Wu Liming ${ }^{1, a}$, Zhang Qiaofen ${ }^{1, a}$ \\ ${ }^{1}$ School of Information Engineering of Guangdong University of Technology, Guangzhou, China \\ adengyaohua@gdut.edu.cn
}

Keywords: engineering education, innovation pioneering ability cultivate, technological competition

\begin{abstract}
Innovation and entrepreneurship for college students cultivate a new era of higher education is an important content, technology innovation and entrepreneurship competition is the main vehicle for capacity building and platforms. Universities to carry out scientific and technological competition can stimulate innovation and entrepreneurial potential college students, the majority of young students to cultivate innovation and entrepreneurship skills and teamwork spirit, improve the quality of students' scientific and technological innovation, scientific and cultural prosperity of the campus, and to promote research with the close integration between, can play positive role in promoting, is to train high-level, high-quality, all-round development of innovative talents and effective way.
\end{abstract}

\section{Introduction}

"CPC Central Committee and State Council on deepening education reform and the decision to promote quality education" and the Ministry of Education to develop a "21st Century Education Revitalization Action Plan" clearly states: "the combination of education with productive labor is to develop a comprehensive talent development an important way" Encourage universities, research institutes and enterprises in the innovation and development of high-tech industries to carry out multi-form multi-industry-academia pathways and comprehensive cooperation, so that universities become truly high-quality, high-quality personnel training base and high-tech research and development of an important source of radiation incubators. "Ministry of Education, and comprehensively improve the quality of higher education on a number of observations (4th high teach [2012])" on the innovative training model, noting that the implementation of outstanding engineers through education and training programs to improve the practical ability to focus, to explore with the relevant departments, research institutes, industries and enterprises in joint training mode.

\section{Necessity of cultivating students' innovative entrepreneurship ability}

With the rapid development of higher education, as personnel training of local engineering colleges also face more than the number of students, the regional economic development of local talent demand and changes in key institutions. Therefore, as a local key institutions, both teaching and research, both scientific and technological research, innovation and academic knowledge of top-notch talent, but also attach importance to application-oriented talents, we must establish a classification training personnel training system for the local economy building diverse talent for building an innovative Guangdong, promote industrial restructuring and upgrading to provide a strong pool of talent. Guangdong Province, Guangdong University of Technology as a key construction to engineering -based university in the forefront of reform and development of the Pearl River Delta, has long insisted school-enterprise cooperation school teaching model, focusing on the cultivation of students' practical ability for economic and social development in Guangdong Province training a large number of engineering applied talents. Guangdong University of Technology in order to adapt to the era of the information society needs to improve a variety of academic competition platform and teaching resources, the students' ability to develop innovation and entrepreneurship as an important task.

\section{Building science and technology competitions platform}

Information Engineering College 800 people each year to recruit 3200 students, currently setting 
up communications engineering, information engineering, measurement and control technology and professional equipment such as three undergraduate majors (including six professional or orientation) information engineering, including electronic information engineering direction and the direction of application of electronic technology, measurement and control technology and professional equipment including computer control macaronis direction and orientation.

In order to give full play to the strengths of these students, students interdisciplinary collaboration and innovation capacity, the need to establish an effective platform for academic competitions. Science and technology competition platform is a comprehensive competition platform management mechanism relates to the contest, contest teaching system, network media contest, contest promotion, science and technology competitions base funding for science and technology competition and technological competitions teachers and so on. Only the regime and supporting the implementation of hardware and software, in order to ensure the effective implementation of scientific and technological innovation activities. School based on the actual situation on the following areas for construction.

\section{(a) establish science and technology competitions material security platform}

Funding is to be carried out in academic competitions important material guarantee. Fund mainly two aspects: one is used to establish a science and technology competition practice base, the relevant aspects of the laboratory and contest entry fees for the students to learn, experiment, internships provide the necessary space and facilities. The second is to give the contest and achieved excellent results for students and instructors certain subsidies and preferential policies. In addition, the university also actively working with tech companies to establish a close partnership based on mutual benefit, actively seek the support of social capital to enable students to diversify the sources of funding for scientific and technological innovation to promote the cultivation of innovative talents.

\section{(b) strengthen building science and technology competitions instructor team}

Building technology race of the "think tank" platform of teachers as academic competition of the guide, from training to players before the game coaching, mentoring teachers has an indispensable role. The establishment of science and technology competitions instructor jobs, hiring high-level instructor, the formation of high-quality technology race instructor team, work outstanding instructor giving appropriate incentives to attract more outstanding teachers added to the technology race instructor team. At the same time, strengthen the science and technology competitions instructor team communication, education and training to improve teachers' professional guide scientific and technological level of competition, technological competition forever "think tank" platform of youth and vitality.

\section{School-enterprise integration to promote students' practical ability to enhance}

In order to better promote the reform of teaching and improve the quality of teaching, the hospital actively promote school-enterprise cooperation , Combination pace, our hospital has with Guangdong Midea Group , Huizhou Huayang Group, Datang Mobile , Huawei, Beijing Bo Chong and other famous enterprises have close cooperation, through the combination of high-tech industries on the one hand the development of a "talent pool" of new technology and information and IT, while promoting school personnel training work, and achieved fruitful results. Mainly reflected in the following aspects.

In recent years, there have been more than 190 people in the students and the Guangdong Provincial Science and Technology won the national competitions, making all kinds of awards, such as in the "Challenge Cup" university student extracurricular activities and technology work competition has won numerous awards at several provincial prize, based on the 2003, 2009, 2011 National Award second prize and the national first prize; Since 2001, received numerous National Undergraduate Electronic Design Contest first prize, Guangdong Province, the first prize; Since 2001, the country received numerous mathematical modeling contest, second prize, first prize, Guangdong Province, since 2006 to received numerous national college "Free scale" smart car competition, country, South Division first prize, second prize and so on. Students' innovation, entrepreneurship and engineering technology development capabilities continue to improve. 


\section{Experience of university students' innovation and entrepreneurship cultivating based on technological competition}

In recent years, the school continued to deepen promote the "Students 'Innovation Action Plan" , through the "Challenge Cup" competition, electronic design competitions to enhance students' practical ability, innovation ability and professional skills. Through years of innovation and entrepreneurship for students training mode of exploration, we understand that innovation applied talents training should focus on "Xuesi combination", "Unity of Knowledge" " individualized".

\section{(a) personally, high school teacher, guide students to independent innovation}

Students' innovative practice ability, has long been leading Information Engineering, secretary and chief advocate and advance a priority, through our efforts over the years, the achievements are obvious to all.

Scientific Innovation Ability as a college student an important part, from freshman year had begun. Newly enrolled students ability to accept new things, thinking, active, eager to realize their ideas. However, they still lack key point to find the ability to solve problems. Therefore, students in introductory stage of technological practice personal guidance of a teacher is very important. Technological innovation practice time and regular teaching time there is a certain contradiction, in order to ensure that students not to delay the theoretical courses of study, we take advantage of summer vacation and other holidays time, carry out technological innovation practice. In the lab, the teacher and students together to discuss theoretical approaches together to solve practical problems and overcome various difficulties. This face to face guidance technology will not only allow students to understand the creative process, and more importantly, through the words of the teacher teaching by example to guide students to embark on the road of scientific and technological creation.

Allow students to experience the actual creation of the first sense, let them know that they are also able to design a simple work, understand the hardships of the road of scientific and technological creation. This process give students experience and confidence than anything else.

Students participate in scientific and technological innovation activities better foundation, hands-on ability. Guide them in the sense of innovation and innovative spirit, the need to break the routine. In theory, should mean that they learn a variety of professional knowledge; program design have advanced awareness, encourage them daring to try new methods, new techniques and new tools; during the design process to motivate them Ganpin, Ken drill spirit.

In the National Undergraduate Electronic Design Contest, many participating students in program design are often the most commonly used methods and implementation tools, such an approach usually reach better results. 2009 National Electronic Design Contest We have several teams chose the "digital equalizer amplifier", the conventional method is to use digital filtering plus analog amplification, and then use a general microprocessor control can be realized, however, adopt this method design narrow pass band equalizer output fluctuations, certainly can not meet the target. As a bold attempt to provide guidance to students before the use of new signal processing algorithms, and using a high-speed embedded chip design preparation, after four days and three nights of hard work, they work not only meet the specification, are given awards, including an entry teams of students work using a unique approach, and the output is hardly any fluctuations division when experts gave out won the National Award.

In addition, to help students develop awareness of innovation, but also can guide students to learn outside of the professional knowledge and encourage them to carry out interdisciplinary design work to improve their creativity. For example: In 2010 at the National embedded design contest, we have a group of teams in the design, skillfully popular architectural design philosophy applied to the design of their model works, works very vividly demonstrated their design ideas, visual effects, refreshing, by the evaluation experts alike, and was named the game works best on a public demonstration at the award ceremony.

\section{(b) who is the norm, and students to become mentors}

Scientific and technological innovation in the practical ability of students to guide the process, care for students' thinking and help them determine the objective of the struggle is an important part. 
Each participant Technology practice activities are directed at the students began to come to their own preferences, but they are the type of talent on the current needs of the community but know less, if combined with the direction of employment after graduation, and guide them in related fields creation of science and technology, it can stimulate the enthusiasm of their in-depth study. At this stage and students talk to a friend's identity and students talk about the goal of life, more about some of the successful examples of graduates, creating opportunities for students to reach out to more cutting edge of technology.

Educator Kalinin said that the impact of teachers to students is "any textbook, any moral maxim, any punishment and reward systems are not a substitute for an educational force." Teachers and students with the growth, and students to become mentors, not only to narrow the distance between teachers and students, but also to enable students to understand, understand and accept the teacher's educational thinking, while respecting the demeanor of the students, so that students feel their teachers care and love.

The ancients said: lax in teaching, teacher is lazy, Yan is love, pine is harmful. Strict teacher a great day, and only for students strict requirements in order to tap the potential of the students, making the creation of students in science and technology on the road, go higher, farther.

"Starting in toil, closing knot in the flat", we believe that under the leadership of the school, and college levels of leadership and the efforts of fellow teachers, our teaching and training students' ability levels will scale new heights.

\section{Conclusion}

Technology Competition and university education are inseparable, science and technology competition is the ultimate expression of students overall quality, innovation and entrepreneurship, the ability to adapt to social and economic development needs, and students' innovative entrepreneurship is a core element of the quality of talent or detect critical points. Universities to carry out scientific and technological competition can stimulate innovation and entrepreneurial potential college students, the majority of young students to cultivate innovation and entrepreneurship skills and teamwork spirit, improve the quality of students' scientific and technological innovation, scientific and cultural prosperity of the campus, and to promote research with the close integration between, can play positive role in promoting, is to train high-level, high-quality, all-round development of innovative talents and effective way.

\section{Acknowledgements}

This work is partially supported by Education Teaching Reform project of Guangdong University of Technology (2013Y008) (2012ZZ01). Thanks for the help.

\section{References}

[1] Wang Ying, Zeng Xia, Exploration and research about cultivating innovation ability with university students' technology competition, Guangdong Chemical Industry, vol.39, no.15, P187-189, 2012.

[2] Li Weiwei, Gao Qinghua, Science and engineering university students' ability of innovation cultivating based on technology competition, China Electric Power Education, no.4, P171-174, 2011.

[3] Li Ning, Exploration of university students' innovation ability cultivating mode based on technology competition platform-- Institute of Mechanical and Electrical Engineering in Hunan University of Technology, Contemporary educational theory and practice, vol.4, no.6, P70-72, 2012 [4] Lin Wenqing, analysis of university students' innovation ability cultivating based on technology competition, Technology and Management, vol.12, no.2, P141-144, 2010.

[5] Wang Yeshe, Wang Fangyin, Xiang Wenjiang, Research and practice of university students' technology competition and innovation ability cultivation, China Electric Power Education, no.10, P187-189, 2013. 